\title{
Bare Strength: representing veterans of the desert wars in US media
}

\author{
Jenna Pitchford-Hyde \\ University of East Anglia, UK
}

\begin{abstract}
Until recently injured veterans of the Afghanistan War (2001present) and the Iraq War (2003-2011) were significantly absent in US media. However, veterans are becoming increasing visible in mainstream US media. This article suggests that the initial reluctance to represent injured veterans stemmed from the deep-rooted governmental and military need to reinforce the ideology of a masculinised US identity. American masculinity relies on the preservation of the hyper-masculine 'all American hero', hence the previous invisibility of injured or 'damaged' veterans in the media. However, the new wave of veteran images which is rapidly coming to the fore in US media indicates a shift in public perceptions of veterans. The central focus of the article is the recent increase in the visibility of veterans in US media, with veteran Noah Galloway featuring on prime time television show Dancing with the Stars, and photographer Michael Stokes' photobook and online projects Bare Strength and Always Loyal featuring injured veterans of the Afghanistan and Iraq wars. While increasing the visibility of veterans in the media is commendable, Dancing with the Stars' and Stokes' representations present their own difficulties in terms of the narratives used by each to depict the veterans. Through a close textual analysis, this article examines how representations of injured veterans in US media have been transformed, explores the reasons for this shift and identifies the potential problems with the more recent depictions.
\end{abstract}

Keywords: Afghanistan, disability, image, Iraq, media, veteran, war

\section{Introduction: invisible soldiers, militarised masculinity, and media representations}

Until recently, injured veterans of the Afghanistan War (2001-present) and Iraq War (2003-2011) were notably absent in popular US media. While a select few veterans have featured as examples of the idealised 'American hero' or the 'dangerous/damaged veteran' (Horton, 2013; Jordan, 2012), the vast majority, especially those suffering from psycho- logical or physical combat trauma, remained notably hidden from public view (Alpert et al., 2007). This article suggests that the initial reluctance to represent injured veterans in the US media stems from the need to reinforce the deep-rooted ideologies regarding US national identity and masculinity that influence government policy making. Upholding ideological notions about gendered national identity has been fundamental to the military in the struggle to maintain public support for the conflicts in Afghanistan and Iraq. Julie Drew (2004) suggests that fear and vulnerability in the aftermath of the 11 September ter- rorist attacks were associated with weakness and femininity, with the media constructing 'an assertively masculine alternative by playing up "narratives of heroism" from New York City firefighters and rescue crews' 
(Drew, cited in Christensen, 2008: 291). The associa- tions between the military, gender and national identity played out in the US media to cre- ate a narrative focused on the importance of what Iris Marion Young identifies as 'the logic of masculinist protection' (Young, 2003). In the case of 9/11, the masculinist protection narrative suggested that the US military (symbolising US masculinity) would protect femi- nised US civilians from the 'bad guys'. US media, Christensen suggests, plays a funda- mental role in constructing and maintaining the discourses of masculinity with which the US government and military align themselves (Christensen, 2008: 290).

The importance of maintaining such discourses has significant implications for the representation of injured veterans. George J. Annas (2008) suggests that there were con- flicting demands placed on military doctors by the perceived 'military necessity' of cre- ating the image of a masculinised America fighting a 'good' war, and the 'medical needs of the individual soldier' (p. 1088). Annas observes that the War on Terror placed mili- tary physicians under significant pressure to 'retain soldiers in combat areas or return them for another tour of duty' (Annas, 2008: 1088). Here, Annas identifies the conflict- ing interests of war and medical care: with increased pressure to return soldiers to the combat zone quickly, medical ethics guidelines regarding psychiatric care were often compromised. Crucially then, some veterans of the Afghanistan and Iraq wars have suf- fered physical or psychological injuries due to the pressures of military policy that aspired to maintain a positive media image of the US military and the war. Consequently, images of these injured veterans remained absent from American television screens for a considerable period of time. Steven $\mathrm{H}$. Miles argues that the military and governmental decisions to reinforce dominant discourses of war and preserve masculinised US identity often outweigh the necessity for truth (Miles, 2013: 117). Since US masculinity relies heavily on the preservation of the able-bodied, hyper-masculine, all American hero, many injured veterans find themselves renegotiating their own identities and occupying positions of marginality in media discourses of the wars. For US audiences, the image of the injured, disabled or psychologically damaged veteran does not equate to the media construction of the cowboy hero fighting the 'good fight' (Christensen, 2008: 291).

The limitations placed on media representations by the need to reinforce discourses of masculinist protection heavily impact public understanding of veterans' experiences and the difficulties they face. W. Lance Bennett, Regina G. Lawrence and Steven Livingston suggest that 'information that may be crucial for understanding and evaluating the stories in the headlines is often unreported or woefully underreported because it simply is not sanctioned by the powerful sources that drive the news' (Bennett et al., 2007). Interestingly, 2015 witnessed a shift in representation, with injured veterans finally appearing in US media formats in roles which attempt to challenge the dangerous/dam- aged veteran stereotypes. This article takes as its focus the representation of injured veterans in two distinct, but interconnected media formats: the prime time television show Dancing with the Stars (US series, ABC, 2015, from herein referred to as DWTS), and photographer Michael Stokes' photobooks Bare Strength and Always Loyal (2014 and 2015) which he also promotes through social media such as Instagram 
This article situates DWTS as belonging to the subgenre of television that Frances Bonner (2011) and Misha Kavka (2012) identify as 'reality talent' (which follow the contestants as they develop a new skill), while Stokes' work is most usefully interpreted as what Xavier Pick terms 'visual storytelling' (2008-2009). Although the formats are quite different in many respects, this article argues that the narratives that both DWTS and Stokes construct to frame their veteran subjects share several commonalities and challenges in terms of representation. In its construction of veteran Noah Galloway's narrative, DWTS' short films are designed to introduce the contestant prior to his dance, adopting the aesthetic trappings of documentary in an effort to signal authenticity. Crucially, the films necessarily encompass a narrative element which invites the audi- ence to engage with Galloway and his journey on DWTS. It is the development of this narrative, and its focus on the hard work required to succeed (Bonner, 2013: 266), which promotes a continued engagement with each series rather than watching episodes spo- radically. Similarly, much of the impact of Stokes' images lies in his visual storytelling (Pick, 2008-2009). The image of each veteran is framed by an overarching narrative which Stokes constructs in order to evoke an emotional response from the audience and a sense of connection with the veteran. Crucially, this article argues, both DWTS and Stokes' framing of their veteran subjects make a claim for documentary level authentic- ity while constructing partially fictionalised narratives in order to maximise their impact. Jonathan Bignell (2009) claims that "there is a tension between producing a documentary which is representative and "accurate" and providing the audience with a programme which conforms to the conventions of argument and storytelling' (pp. 201-202). It is this tension, identified by Bignell in relation to documentary, which presents the most significant challenge to DWTS and Stokes, and lies at the root of this article's analysis. While increasing the visibility of veterans in the media is commendable, this article sug- gests that DWTS' and Stokes' representations present their own difficulties in terms of how narrative can impact the representation and public perception of veterans. Drawing on debates in disability, television and gender studies, this article explores the ways in which DWTS and Stokes navigate the complex trajectory of representation in the narra- tives they construct for their injured veteran subjects. Perhaps most importantly, this article explores how the representation of these veterans reinforces and/or challenges dominant discourses about militarised masculinity and US national identity in the US media.

\section{Performance, prosthetics and 'passing': negotiating disability and gender in DWTS}

In 2015, the US mainstream media took its first tentative steps towards raising the profile of wounded veterans with the inclusion of a physically injured US Army Sergeant, Noah Galloway, on the prime time television show DWTS. Galloway was injured during Operation Iraqi Freedom by an improvised explosive device (IED), resulting in the amputation of his left arm above the elbow and his left leg 
above the knee. While inclu- sion of Galloway on the show acknowledges the necessity to make veterans more visible, his participation in a dance competition against able-bodied contestants raises some dif- ficult questions about the public perception and media representation of disability in the United States. The difficulty for the producers of DWTS lies in navigating the trajectory between increasing the media presence of disability (especially amputee veterans returning from the Afghanistan and Iraq Wars) and the danger of enabling a contrived form of voyeurism. The decision to feature disabled non-celebrity Galloway on DWTS, a show usually reserved for able-bodied celebrities, immediately identifies him as different. DWTS explores Noah's physical and emotional vulnerability, while showcasing his abil- ity to perform dances which are, at first glance, seemingly impossible for an amputee. 2 How, then, is the audience of DWTS expected to respond to Galloway's performances? Mitchell and Snyder (1997) suggest that able-bodied audiences are caught in a dichoto- mous relationship with the image of the disabled body:

Representational media secure our attention as readers and viewers in the double bind of our fascination/repulsion with physical difference ... We experience disability through an anticipation of our desire to 'know' the secret of labyrinths of difference, without significantly challenging our investment in the construction of difference itself ... (p. 15)

The complex relationship that Mitchell and Snyder describe is explored through Galloway's appearance on DWTS and the narrative that the show constructs for him through the introductory films which are played prior to each of his dance routines. Bonner (2013) suggests that such short films are essential to audience engagement with the reality-talent format:

It is the continuity between episodes which enables a developing backstory about the contestants to be screened ... part of the content of this for celebrities and ordinary contestants alike is a focus on the work required to hone a performance. (p. 169)

Bonner suggests that despite its popularity, the DWTS format is so rarely mentioned in scholarly work that it should be considered as an example of what Brett Mills (2010) calls 'invisible television' (p. 2). While academic analysis of the show's format, espe- cially the short films, has been slow to emerge, I would suggest that they are most use- fully analysed in terms of their adoption of a documentary style. In particular, the short films make use of what John Corner (2006) identifies as an 'economy of intensity' (p. 90), specifically in relation to particular 'speech events'. In DWTS, such intensity is cre- ated most effectively through Galloway's recollections of sustaining his combat injuries. These speech events are included over the course of the series, but the intensity is most explicit in Galloway's introductory film for episode 4 which provides a detailed account of combat, his injuries and his experience of post-traumatic stress disorder (PTSD). Corner (2006) explains that such moments can be perceived as dramatic in two senses: something sensational or surprising, or something that is scripted or fabricated by the programme-maker (p. 91). The ways in which Galloway's story 
is depicted in these short films provide concentrated snapshots of how disabled veterans are represented across US media. Crucially, these films illustrate how well-intentioned attempts at representation can often be detrimental to the veterans they are intended to help.

From the beginning of the series, Galloway is introduced as an amputee veteran of the Iraq War and immediately positioned as markedly different from his fellow com- petitors, as well as distinct from the largely able-bodied audience. Lennard J. Davis claims that "the idea of biophysical "normality" is a core value in western culture'(1995). Consequently, Galloway's inclusion in the show due to his combat injuries identifies him as different and reinforces dominant ideas about biophysical normality. Kevin Patterson and Bill Hughes (2000) suggest that 'the hegemonic notion of the disabled body con- structs it in terms of corporeal or intellectual "deficit" (p. 39). Michael Oliver goes fur- ther, asserting that in the West, and especially the United States, 'hegemonic culture promote[s] images of disabled people as either more or less than human' (Oliver, quoted in Riddell and Watson, 2003: 10). While bringing images of injured veterans to main- stream television is commendable, DWTS runs the risk of creating narratives which simultaneously reinforce stereotypes of veterans as either sub- or superhuman. However, the crucial point to note is that Galloway's own perception of his journey differs from the narrative the show sets out to construct for him. In the first introductory film of the sea- son, Galloway claims, 'I don't just want to do well as the guy missing an arm and a leg. I expect more and that's where I'm struggling with it' (DWTS, ep. 1). With this statement, Galloway simultaneously expresses his desire not to be treated as different, but also admits that he, unlike his able-bodied fellow contestants, encounters difficulty when he expects more of himself than merely producing a good 'disabled' performance. Carla Filomena Silva and P. David Howe (2012) suggest that many disabled people 'tend to wish for less than they can be, achieve and have' because they view themselves as inferior and capable of achieving less than able-bodied people (p. 177). This is not the case for Galloway who sets high aspirations for himself. However, at the root of his psycho- logical challenge is the fact that 'the bodies of individuals with disabilities are often compared to "normal" functioning bodies' (Snyder and Mitchell, 2001: 367). This is reinforced in episode 3 when Galloway's choreographer, Sharna Burgess, puts pressure on him to wear a cybernetic prosthetic arm in order to dance the Argentine Tango. Burgess emphasises the importance of achieving 'a complete frame for the first time', overtly equating Galloway's usual lack of arm as a deficit in the terms that Patterson and Hughes suggest. However, Galloway is deeply distressed by having to use the prosthetic. He explains, 'Sharna's excited. It stresses me out because I haven't worn an arm so I'm not only trying to adapt to it, but I'm being thrown right in at the deep end and having to perform with it'. After unsuccessfully attempting to rehearse with the arm, Galloway declares, 'I hate the $\mathrm{f}^{* *}$ king arm', which finally prompts Burgess into adapting the dance so it can be performed without the prosthetic. This event raises two important issues. First, the refusal of Galloway to wear the prosthetic arm (and Burgess' obvious disap- pointment in her partner for not achieving a complete frame) highlights the complexity of people with disabilities competing against able-bodied contestants. Here, Galloway is made to feel like a 
failure for being unable to achieve a 'normal' frame for the tango. But, as Christa van Kraayenoord (2009) asks in relation to the inclusion of a blind Paralympian competing on the Australian version of DWTS, is judging disabled and ablebodied con- testants on the same criteria fair (p. 315)? In DWTS, the issue of whether accommoda- tions should be made for disabled contestants is never explicitly addressed. Instead, it is implied that Galloway will be judged on the same criteria as the other dancers. This approach, however, is potentially problematic since it reinforces the necessity of Galloway performing a 'normal' dance routine. As witnessed in week 3, Galloway expe- riences pressure to use prosthetics in order to achieve a 'normal' dance with a complete frame. However, unlike previous amputee contestants Heather Mills and Amy Purdy, Galloway's leg injury is above the knee which means that he is limited by the level of flexibility in the artificial knee joint. This, together with the fact that he cannot get on with using the prosthetic arm means that he is unable to 'pass' as an ablebodied dancer, even with prosthetics. Whereas 'Mills used a prosthetic leg to pass as an able-bodied individual and avoid being seen as a "freak" (Quinlan and Bates, 2008: 67), the limita- tions of Galloway's prosthetic leg and his inability to use the prosthetic arm actually accentuate his difference, positioning him as less than human and threatening his mascu- line identity. In her discussion of prostheses in relation to breast cancer survivors, Iris Marion Young (2005) argues,

Prosthesis and reconstruction give primacy to the look, to the visual constitution of a woman's body. Her trauma is constructed not as the severance of herself and her loss of feeling, but as her becoming visually deformed, repulsive to look at. She must protect others from viewing her deformity and herself from the gaze of repulsion. (p. 95)

While Galloway's experience might not be that of desexualisation in the same way as a woman following breast cancer treatment and a mastectomy, we can read DWTS' representation of him using Young's argument. Galloway's inability to use prosthetics to 'pass' as an able-bodied dancer highlights his vulnerability as an amputee. The defi- ciency of his missing limbs is accentuated and he is clearly not able to perform the same moves as the able-bodied dancers. When Galloway expresses frustration at the lack of flexibility in his prosthetic leg in week 5's show, Burgess' response is the emas- culating comment 'Suck it up Princess'. Quinlan and Bates (2008) observed that 'Heather Mills [was] expected to be as close to able-bodied as possible, as well as attractive, in order to be accepted as a dancer' (p. 76). For Galloway, however, the insistence of media in attempting to normalise disability by using prosthetics in order for disabled people to perform able-bodiedness undermines his masculinity. Consequently, he is positioned as 'less than a man', thus threatening both his gendered and militarised identities.

\section{Masculinising the supercrip}

A demoralising story of a disabled veteran losing a dance competition against his able- bodied peers would not, however, make for especially good televisual entertainment. As such, week 4 witnesses a shift in the narrative that DWTS constructs for Galloway. Instead of attempting to 'pass' as an able-bodied dancer, 
Galloway is now positioned as a 'super- crip', that is, 'a person with disability who performs ordinarily in his or her daily life or really excels' (Kama, 2004). Silva and Howe (2012) suggest that often in discourses sur- rounding disability, "people with impairments become "super" in contexts where an able- bodied individual would just be an ordinary person' (p. 175). Galloway is positioned as supercrip in several ways, but primarily, he adheres to Hardin and Hardin's (2004) defini- tion of 'the disabled person as heroic by virtue of his or her ability to perform feats nor- mally considered not possible for people with disabilities or by virtue of the person living a regular life in spite of a disability' (Section 5.3). Such supercrip narratives can be problematic, argue Silva and Howe (2012), because they 'can be considered to be an expression of society's low-level expectation placed upon people with disability, which ultimately perpetuates the understanding of their existence as a "problem"” (p. 175).

Galloway's narrative on DWTS is ultimately defined by his categorisation as a super- crip. From the start of the series, Galloway counters his positioning as demasculinised and disabled with a supercrip narrative which documents his journey to 'overcoming' his disability, claiming, 'What I'm lacking in limbs I'll make up for in determination and hard work' (DWTS, ep. 1). Here, Galloway indicates that one can overcome disability if one just tries hard enough. This is a narrative discourse which Bonner (2013) argues is unique to the reality-talent format:

Reality-talent shows, whether they involve ordinary or celebrity contestants, are one place on television where work is extolled and shown; indeed it is in showing the work that is done to produce an improved performance that reality-talent differs from the older talent shows. (p. 177)

For a disabled contestant, this can become a somewhat dangerous narrative, suggest- ing to the able-bodied public that all disabled people could overcome their disabilities given enough strength of character and hard work. Essentially, the claim of such 'over- coming' narratives is that 'an individual with a disability can be re-abled' (Quinlan and Bates, 2008: 76). Galloway's narrative further enforces this with the introduction of his \#NoExcuses campaign. \#NoExcuses is a charitable fund that Galloway set up to raise money and awareness for organisations that support fitness, wellness and inspiring oth- ers to enlist healthy habits in their daily lives.3 However, Galloway's constant reminder of the hashtag on his T-shirt in weeks 4 and 7 reinforces his 'overcoming' narrative, with an emphasis on psychological battles enabling physical success. This is the narrative Galloway sets up for himself. However, DWTS constructs a much stronger 'overcoming' narrative, emphasising the difficulties he has overcome since he was injured in addition to his DWTS journey. This is most evident in week 4's episode which provides the viewer with a more detailed background into the circumstances of Galloway's disability.

Over the whole series, this is the speech event which delivers the most intensity in the terms that Corner defines. Galloway describes how his combat injuries were sustained in an IED explosion in Iraq in 2005 and reveals his personal experience 
of PTSD. He claims that the injuries he sustained were necessary to drive him on to 'the journey of accept- ance from the man I was to the man I've become' (DWTS, ep. 4). Galloway's overcoming journey is illustrated for the audience in a deliberately evocative contemporary dance performance to Toby Keith's 'American Soldier' (2003). Keith's song focuses on the timeless traits of an American soldier (that he or she is just, loyal and brave) with the implication that Galloway embodies this idealised image of the American soldier. Galloway performs the dance with only trousers on. The trousers are cut high on his left leg to expose his prosthetic while his upper body is naked, exposing his injured limb. Although Galloway's costumes are often deliberately tailored to highlight his prosthetics and physique, this particular example renders him utterly exposed. In contrast to this show of vulnerability, though, Galloway's muscular physique is also on display, rein- forcing the overcoming narrative with a physical illustration of the strength needed in order for him to achieve success. However, what makes this the most intriguing part of the DWTS narrative constructed for Galloway is the response and feedback of the judg- ing panel. Following Galloway's performance, the judges break away from their usual relatively objective evaluations, and are all visibly emotional, with Julianne Hough moved to tears. While Hough's emotional response could be interpreted as pity, the other three judges strongly reinforce the overcoming narrative. Carrie Ann Inaba likens Galloway to a Haiku, telling him, 'although maybe some of the movements are smaller or your vocabulary is less than some of the other contestants, it was more profound than most' (DWTS, ep. 4). Here, Inaba openly acknowledges that Galloway is not always performing at the same technical level as his peers, but that due to his overcoming narra- tive, his performances capture a power of emotion that the others do not, thus reopening the debate about the fairness of able-bodied and disabled veterans being judged on the same criteria. Bruno Tonioli labels Galloway a 'superhero' and 'ultimate role model', while Len Goodman concludes, 'You are an inspiration and I think everyone here should stand up and applaud you' (DWTS, ep. 4). It cannot be claimed in this episode that Galloway is being treated in the same way as his able-bodied counterparts. Following his failure to use the prosthetic arm and pass as an able-bodied contestant in the previous episode (thus emphasising his deficit, emasculating him and positioning him as less than human), in week 4, DWTS reconstructs Galloway in the role of supercrip. The show emphasises his status as superhuman not only through his achievements in his perfor- mance but reminding the audience, both in his pre-dance narrative and the judges' com- ments, of the sacrifice he has made for his country, thus directly reinforcing Young's (2003) 'logic of masculinist protection'. His deficit is the price he has paid to keep them safe, and his ability to dance despite his injuries elevates him to superhuman, heroic status.

In episode 4, DWTS sets up a narrative which positions Galloway as supercrip for the remainder of the season. He is depicted as one of what Berger (2008) describes as 'those individuals whose inspirational stories of courage, dedication and hard work prove that it can be done, that one can defy the odds and accomplish the impossible' (p. 648). Interestingly, the DWTS narrative appears to be incongruous with Galloway's own per-spective on his participation in the 
show. When presented with the opportunity to per- form a military themed dance suggested by the viewing public later in the season (week 8), Galloway refuses, instead opting to distance himself from the direct associations with the military and therefore avoiding overtly reinforcing the supercrip discourse. Although Galloway's own narrative differs from the DWTS commentary to some extent, both strongly adhere to the overcoming narrative, with Galloway concluding that if he keeps up the hard work, he may 'have a shot at winning the competition'(DWTS, ep. 8). Central to Galloway's narrative in DWTS is his construction as a supercrip, and crucially, it is the narrative constructed around overcoming his disability which elevates him to the cate- gory of superhuman and reinforces his masculine identity. As the season progresses, the viewer is continuously reminded of his veteran status and he is repeatedly constructed as an American hero. His overcoming narrative, masculinity and soldier identity are ulti- mately bound to his identity as an American. Through the media depiction of Galloway, the viewer experiences continuous reinforcement of the image of the War on Terror as a just conflict, the strength of the US military and, more broadly, the importance of pre- serving US national identity and the hegemonic ideology.

\section{Shooting disability: militarised masculinity in Bare Strength and Always Loyal}

Photographer Michael Stokes takes a more radical approach to representing veterans of the War on Terror and negotiating masculinity. In recent years, Stokes has become well known for photographing injured veterans of contemporary wars. While Stokes was working on a photobook project titled Masculinity (2012), he was introduced to Corporal Alex Minsky whose right leg was amputated as a result of an IED explosion in Afghanistan. This meeting steered Stokes away from his previous topic of sports photog- raphy and towards projects aimed at representing injured veterans of the Iraq and Afghanistan wars. His photobook Bare Strength (2014) features a section dedicated to representing veterans, specifically amputees, while his later photobook project Always Loyal (published in 2015 and titled after the English translation of the Marine Corps motto 'Semper Fidelis') focuses exclusively on 14 veterans of contemporary American wars. Stokes explains how, similarly to Galloway's desire to be treated like his peers on DWTS, Minsky requested to be photographed like any of Stokes' previous fitness models:

I met this veteran, Alex Minsky, and talked to him about different approaches to a portrait session (said Stokes). I had already studied as many amputee photos that I could find. I noticed that most of them emphasized the lost limb, and that the mood was often sorrowful. That was not the vibe I was getting from him, so I decided to simply photograph him as if he were not an amputee, photograph him exactly the same way I would any of my fitness models. (Ledbetter, 2015) 
Here, Stokes suggests that he was anticipating a vulnerable broken veteran, but what he actually encountered was a strong, confident soldier. Although his ethos is one of accept- ance, he concedes that his own preconception of a veteran amputee was one of weakness and vulnerability. Stokes demonstrates his awareness of the tendency of photography to position injured veterans as lacking, and their missing limbs as deficit. In contrast, Stokes' approach is to photograph the veterans as he would his other subjects. He sets up scenes to accentuate their attractiveness, their physical strength and their sexuality. Stokes' insistence that

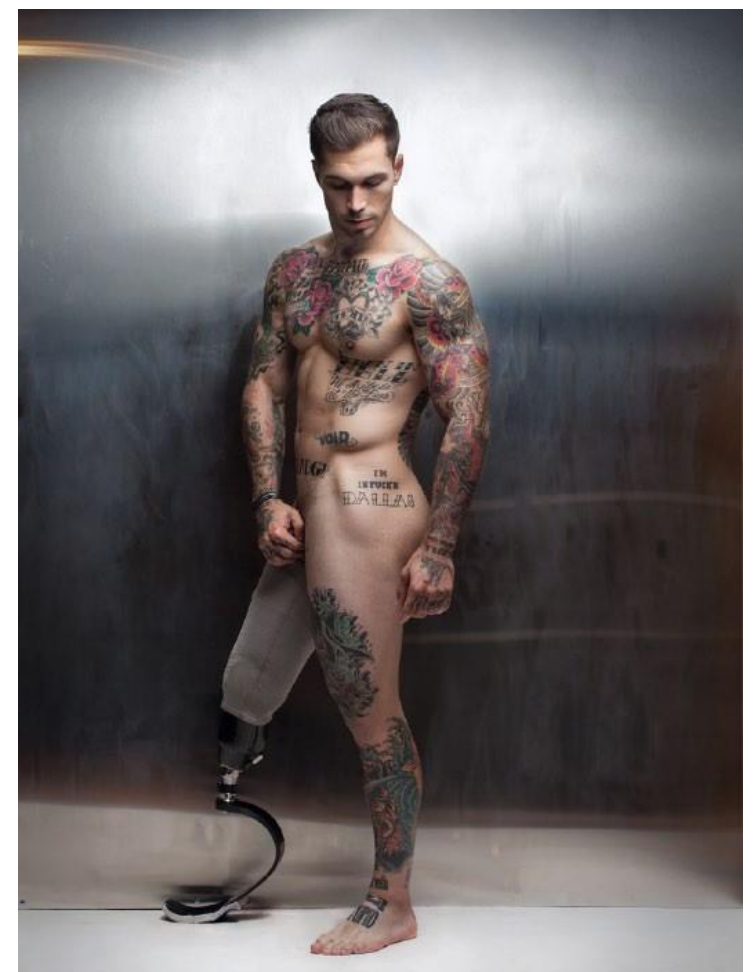

he is shooting the veterans as if they are not amputees is, on the face of it, a huge step towards acceptance of veterans in mainstream US culture.

Figure 1. Corporal Alex Minsky. Afghanistan War veteran, US Army. Copyright Michael Stokes Photography.

Since Stokes' initial interest in photographing veterans emerged from his focus on masculinity, he is acutely aware of the impact of gendered images. Stokes claims that some people have commented 'You're making them feel like men again'. Although Stokes contests this idea, insisting that the veterans he photographs are already healed and confident, such assertions epitomise the representational problem that faces disa- bled veterans in America. The notion that disabled veterans are less than human, and therefore less than the idealised masculine all American hero, remains firmly embedded in US culture. Stokes argues that his erotic approach to photographing the veterans destigmatises disability instead of asking his subjects to perform able-bodiedness. As you can see in Figure 1, Minsky is featured naked apart from his prosthetic and a sports cup covering his genital area. His strength is foregrounded by the accentuation of his muscles. By treating Minsky like his fitness model subjects, Stokes foregrounds his 
masculinity and makes him the subject of the sexualised gaze. However, Stokes' intention is not to make his disabled subjects perform able-bodiedness. Rather than voyeurism or pandering to the curiosity of the audience about the disabled other, Stokes' intention is to enable amputee veterans to showcase their sexuality, irrespective of their disability. In this sense, Stokes is not attempting to restore the masculinity of his veteran subjects (he claims they have already achieved this), but rather, by sexualising them through the narratives he creates, Stokes reinforces their connection to military and the state. Jesse Paul Crane-Seeber suggests that 'militarized male bodies, submissive to the state [through their military service], are rewarded with the sort of sex appeal that only massive symbolic power can bestow' (Crane-Seeber, 2016: 1; Tynan, 2013: 80-81). He claims that

The problem with understanding sexual desire in the context of militarization is that there is no simple one-way transfer from state power into the bodies and pleasures of people. Indirect and overlapping factors combine to shape desires in militaries, their members, and the broader societies they are connected to. (Crane-Seeber, 2016: 7)

For Crane-Seeber, then, the fetishisation of the militarised male body is intimately connected with the subject's submission to the state, commitment to military ideology and ability to reinforce the dominant discourse of a masculinised US identity. Such bod- ies are symbolic of the physical strength and manifest destiny that characterises US iden- tity. The public response to Stokes' images, however, signifies an important moment in how participation in combat interacts with narratives about masculinity.4 Previously, US media discourses had prized the able-bodied hyper-masculine hero. That is, the soldier who had proven his masculinity through his commitment to the state and the achieve- ment of having returned from war unharmed. However, the recent increased visibility of the disabled veteran acknowledges Joanna Bourke's observation that despite what the media discourses of each conflict might lead us to believe, it is imperative to remember that the primary goal of war is to inflict injury and mutilate bodies (Bourke, 1996: 31). The reaction to Stokes' images is significant then because it suggests that the viewing public is beginning to renegotiate the image of the heroic militarised male body and its relationship to American identity. Rather than previous incarnations of the able-bodied hyper-masculine American hero, it is now the image of the disabled veteran carrying vis- ible markers of combat that is revered. These veterans have demonstrated the ultimate commitment to the state in the terms that Crane-Seeber sets out, thus reinforcing their masculinity and nationhood. As such, it could be argued that these veterans are becoming the subject of the gaze not specifically for their disability, but for their demonstration of hegemonic masculinity and commitment to the state in sustaining injuries through com- bat and overcoming disability.

\section{Feminising the supercrip: gendering the female disabled veteran}

One of the most controversial photographs in Stokes' Always Loyal collection compli- cates the readings of Galloway's and Minsky's narratives by featuring a female soldier, Sergeant Mary Dague (Figure 2), who lost both arms while 
working as a bomb disposal expert in Iraq. While Always Loyal also features other female veteran amputees such as Shaholly Ayers, Dague's image is especially noteworthy. Dague is not only a female vet- eran and amputee, but also a breast cancer survivor.

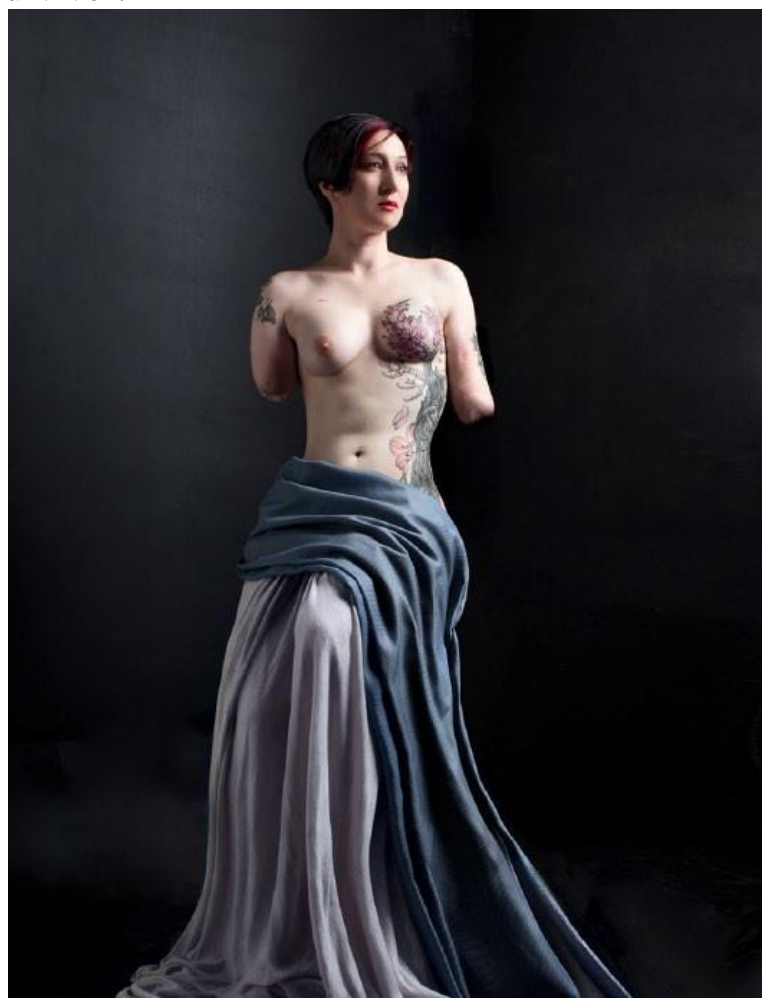

Figure 2. Uncensored photograph of Iraq War veteran Sergeant Mary Dague, EOD tech, US Army and breast cancer survivor. This photo has been removed by Instagram and Facebook, both citing a violation of their Community Standards and Guidelines. Copyright Michael Stokes Photography.

As such, Dague's image calls for a renegotiation of how the gender identities of soldiers are represented in the media. The narratives discussed in this article regarding the preservation of US masculinity through overcoming narratives and military identity are complicated by the inclusion of a female combatant. Additionally, Dague's status as a breast cancer survivor requires an analysis of how her body and its representation renegotiate both her soldier identity and gender iden- tity as impacted by the military, injury and cancer. Whereas Galloway and Minsky find themselves constructing their own masculine identities in relation to the dominant gov- ernment narratives (which are aimed at preserving a masculinised US identity), Dague is simultaneously negotiating her identity in terms of her disability, masculinised soldier identity, her femininity in relation to her soldier status and her illness, her amputee status and her post-mastectomy body. So how does Dague's media image navigate the ubiqui- tous nature of normalising her disabled and post-mastectomy body while constructing sexualised images of her body which reinforce the necessity of conforming to the ideal- ised image of femininity? The narrative Stokes constructs for Dague's 
photograph aims to normalise her disability through destigmatising her combat injuries and mastectomy scars. Her image is evocative of the Venus de Milo with her positioned on a pedestal, shrouded in luxurious looking fabric from the waist down.5 The covering of her lower body foregrounds her injured arms which were both amputated above the elbow follow- ing an IED explosion in the Iraq War. Crucially, in Dague's case, the viewer perceives the proof of her masculinised military identity (her disability resulting from combat injury) at the same time as her physical markers of femininity are problematised by her mastectomy scars. Dague's militarised identity is problematised by the evidence of her illness, which is strongly interconnected with her gendered identity. As Lisa Belkin (1996) observes,

There's something about breast cancer that makes it very different from foot cancer or, for that matter any other disease ... it's about body image, it's about nurturing - it certainly is about femininity. It is loaded for women in ways that other health threats are not.

However, Belkin's claim assumes a unified feminine identity has been established before the impact of breast cancer and its treatments. In the case of female soldiers, this is problematic. Crane-Seeber (2016) suggests that women's bodies are fetishised by default in US society and makes the claim that militarised male bodies who align them- selves with the power of the State through participating in combat are similarly desired:

In researching the pleasures of subjection to the state, I am fascinated by how our culture objectifies and fetishizes the militarized male body in ways that are normally reserved only for women's bodies. (p. 11)

What Crane-Seeber fails to address, however, is how the body is culturally constructed in the case of female combatants. We could argue that the desirability of the already fetishised female body is reinforced by the female soldier's commitment to the state. However, it could be argued that the female soldier undermines her femininity by performing masculinity in order to fulfil her military identity, and that her militarised masculinity is undermined by the fact she is female. If this is the case, then female sol- diers cannot achieve the fetishisation of militarised masculinity that Crane-Seeber describes since their femininity conflicts with their masculine militarised identity. Liz Powell emphasises the importance of reading discourses of breast cancer with an awareness of the limitations of traditional notions of femininity. She argues that

the suggestion that a discourse of breast cancer and femininity is both progressive and liberating misses the very important fact that the concept of femininity on which it draws is built on a set of historical and patriarchal values about the role of women. (Powell, 2013: 45)

Consequently, Stokes' construction of Dague's narrative is potentially problematic. It is intended to play out the tandem hero narratives of combatant and breast cancer survivor (with physical indicators of both experiences 
displayed), which would make Dague's image the best example of the supercrip narrative at work in Stokes' collection. However, while the image of Dague, and its subsequent widespread dissemination through the pho- tobook and social media formats, can be read as raising awareness of both disability and breast cancer, the image can also be read as problematising Dague's gender identity. By constructing Dague as a sexualised goddess, Stokes foregrounds her femininity. If, as Young suggests, breasts hold significant cultural meaning as 'the most visible sign of a woman's femininity, the signal of her sexuality' (Young, 2005: 78), then the overcoming narrative Stokes constructs regarding Dague's mastectomy is reinforcing traditional ideas about restoring femininity by indicating that her breasts are 'once again able to function as fetishised objects of the masculine gaze' (Powell, 2013: 50). However, by reading Dague's experience of combat and breast cancer in relation to each other, Stokes attempts to construct Dague as the ultimate supercrip, capable of overcoming the physical trauma of combat in order to fulfil her masculinised military identity, and also overcoming her battle with breast cancer in order to reclaim her feminine identity. While it should be noted that the narrative that Stokes constructs for Dague could be read in terms of reinforcing patriarchal ideas about gender roles, by complicating the militarised image of Dague, the photographer opens up for discussion important issues surrounding gender and disability. Dague's photograph is the best example in Stokes' collection, and in the wider US media, of a veteran image that works to destigmatise disability and illness. Stokes achieves this by explicitly interrogating the relationship between the militarised masculine identity that is borne out of commitment to the state, the feminine identity of female combatants, the problematic gendering of the post-mastectomy body and the masculinised image of the supercrip who overcomes her disability. The strength of Stokes' representations of disa- bled veterans lies in his refusal to offer a single narrative. While his images may remain problematic to some degree, Stokes has identified that the key to representing veterans effectively is in acknowledging the complexity of their identities.

\section{Conclusion: re-imaging disabled veterans in the US media}

By increasing the visibility of disabled veterans, DWTS and Stokes have made a positive contribution to bringing veterans of the desert wars into the mainstream US media via prime time television, print and social media. However, DWTS and Stokes take differing approaches to constructing narratives for their subjects. Through DWTS' construction of Galloway's overcoming narrative, the audience is presented with a supercrip narrative and overcoming story that serves as a reminder of the importance of preserving US iden- tity and hegemonic masculinity. Consequently, the narrative that DWTS constructs rein- forces the ideology that enables US government discourse to construct the Iraq and Afghanistan conflicts as 'just wars' (Astley, 2006), and distance itself from the dubious military policies which Annas (2008) claims left many US combatants vulnerable to injury and death.

It could be argued that the relationship of soldiers' bodies to the state (and the subse- quent reinforcement of US hegemonic masculinity) means that both DWTS and Stokes' images can be seen to objectify disabled veterans to some 
extent (Crane-Seeber, 2016). However, Stokes advances the image of disabled veterans by representing their identities as complex and multi-faceted. He does not intend to reinforce his subjects' injuries in terms of deficit by continually attempting to make them perform able-bodiedness. Instead, by acknowledging the complexity of veterans' identities in the narratives he constructs, Stokes is able to create a dialogue between the 'broken veteran' and 'mascu- linised supercrip' discourses, explicitly examining how the gendered military identity of disabled veterans is negotiated. Stokes' representation of Dague adds another dimension to the ways in which he claims to challenge hegemonic ideology, and exposes the poten- tial difficulties for all female combatants in establishing a gendered military identity. Crucially, through his detailed exploration of the complexity of veterans' identities, Stokes increases the visibility of disabled veterans in the media, raises important ques- tions about media representations of disability and challenges hegemonic conceptions of US militarised masculinity.

By simultaneously emulating documentary aesthetics and constructing emotive supercrip narratives, both DWTS' and Stokes' representations of Afghanistan and Iraq War veterans mark a distinct shift in how injured veterans are portrayed in US media. The popularity of DWTS in mainstream media and the rapid circulation of Stokes' images on social media indicate that audiences are beginning to reject previous conceptions of the injured veteran as 'broken' and demasculinised. Instead, contemporary audiences, guided by the carefully constructed narratives, interpret combat injuries as evidence of militarised masculinity and commitment to the state, thus positioning disabled veterans as the ultimate American heroes.

\section{Acknowledgements}

I would like to thank Michael Stokes for his generosity in giving permission for images from Bare Strength (2014) and Always Loyal (2015) to be reproduced in this article. I would also like to thank Dr Liz Powell and Dr Beccy Collings for the valuable and numerous discussions regarding the topics of disability, prosthetics, and gendering which helped to shape this article.

\section{Funding}

The author(s) received no financial support for the research, authorship and/or publication of this article.

\section{Notes}

1. Michael Stokes' projects are produced as the photobooks Bare Strength (2014) and Always Loyal (2015), but Stokes also showcases his images via social media such as Facebook (https://www.facebook.com/MichaelStokesPhoto/), Twitter (https://twitter.com/stokes_ photo?lang=en-gb) and Tumbler (http://michaelstokes.tumblr.com/), as well as on his website (http://michaelstokes.net/).

2. Other contestants in season 20 included actress Rumer Willis, singer and actor Ryker Lynch and Olympic gymnast Nastia Liukin. Galloway's celebrity status is constructed through his participation in Dancing with the Stars (DWTS).

3. For example, the YMCA of Alabaster, AL and Operation Enduring Warrior, and Homes for Our Troops. 
4. The high levels of support Stokes received in his battle against Facebook censorship (including the creation of a 'STOP censoring artistic photos by Michael Stokes on Facebook' group and a similarly named petition on Change.org) suggests a shift in perceptions of masculinity in the United States, in particular, a wider acceptance of the disabled militarised masculine body.

5. The Venus de Milo depicts the Aphrodite, the Greek Goddess of love and beauty (also known as Venus in Roman mythology).

\section{References}

ABC (2015) Dancing with the stars, season 20 (aired 2015). New York: ABC.

Alpert J, Goosenburg Kent E (directors) and Gandolfini J (executive producer) (2007) Alive Day Memories: Home from Iraq. HBO documentary. New York: HBO.

Annas GJ (2008) Military medical ethics - physician first, last, always. The New England Journal of Medicine 359(11): 1087-1090.

Astley M (2006) That's entertainment: the war of images in Iraq as popular visual culture. In: Baker C, Granter E, Guy R, et al. (eds) Perspectives on Conflict. Salford: European Studies Research Institute, University of Salford, pp. 36-57.

Belkin L (1996) Charity begins at ... the marketing meeting, the gala event, the product tie-in. The New York Times Magazine, 22 December, p40.

Bennett WL, Lawrence RG and Livingston S (2007) When the Press Fails: Political Power and the News Media from Iraq to Katrina. Chicago, IL: University of Chicago Press.

Berger RJ (2008) Disability and the dedicated wheelchair athlete: beyond the 'supercrip' critique. Journal of Contemporary Ethnography 37(6): 647-678.

Bignell J (2008) An Introduction to Television Studies, 2nd edn. London: Routledge.

Bonner F (2011) Personality Presenters: Television's Cultural Intermediaries with Viewers. London: Ashgate.

Bonner F (2013) Gaudy nights: dance and reality television's display of talent. In: Jacobs J and Peacock S (eds) Television Aesthetics and Style. London: Bloomsbury, pp. 251-268.

Bourke J (1996) Dismembering the Male: Men's Bodies, Britain and the Great War. London: Reaktion Books.

Christensen WM (2008) Cowboy of the world? Gender discourse and the Iraq war debate. Qualitative Sociology 31: 287-306.

Corner J (2006) A fiction (un)like any other. Critical Studies in Television 1(1): 89-96.

Crane-Seeber JP (2016) Sexy warriors: the politics and pleasures of submission to the state. Critical Military Studies 2: 41-55.

Davis LJ (1995) Enforcing Normalcy: Disability, Deafness, and the Body. London: Verso.

Drew J (2004) Identity crisis: gender, public discourse, and 9/11. Women and Language 27: 7178.

Hardin M and Hardin B (2004) The 'supercrip' in sport media: wheelchair athletes discuss hegemony's disabled hero. Sociology of Sport Online 7(1).

Horton A (2013) Help veterans by taking them off the pedestal [Blog post]. Available at: http:// www.theatlantic.com/national/archive/2013/11/help-veterans-by-taking-them-off-thepedestal/281316/ (accessed 12 June 2014).

Jordan B (2012) Advocates worry about 'crazy vet' perception. Available at: http://discussions. military.com/forums/thread.jspa?threadID=23147\&tstart=7485 (accessed 10 April 2012).

Kama A (2004) Supercrips versus the pitiful handicapped: reception of disabling images by disabled audience members. Communications 29(4): 447-466.

Kavka M (2012) Reality TV. Edinburgh: Edinburgh University Press.

Ledbetter C (2015) Incredibly sexy photos of veterans shatter all kinds of stereotypes. The Huffington Post, 20 July. Available at: http://www.huffingtonpost.com/entry/veteran-amputees-michael-stokes-always-loyal_us_55a917c0e4b0896514d10fc3 (accessed 20 January 2016).

Miles SH (2013) The new military medical ethics: legacies of the gulf wars and the war on terror. Bioethics 27(3): 117-123. 
Mills B (2010) Invisible television: the programmes no-one talks about even though lots of people watch them. Critical Studies in Television 5(1): 1-16.

Mitchell DT and Snyder SL (eds) (1997) The Body and Physical Difference: Discourses of Disability. Ann Arbor, MI: University of Michigan Press.

Patterson K and Hughes B (2000) Disabled bodies. In: Hancock P, Hughes B, Jagger E, et al. (eds) The Body, Culture and Society: An Introduction. Buckingham: Open University Press, pp. 29-44, p. 33.

Pick X (2008-2009) Journals from war and peace. Available at: http://www.xavierpick.co.uk/iraq/ iraqsketch/iraqsketches.html (accessed 10 February 2016).

Powell L (2013) Refashioning the post-mastectomy body in How to Look Good Naked. Film, Fashion \& Consumption 2(1): 43-54.

Quinlan MM and Bates BR (2008) Dances and discourses of (dis)ability: Heather Mills's embodi- ment of disability on dancing with the stars. Text and Performance Quarterly 28(1-2): 64-80.

Riddell S and Watson N (eds) (2003) Disability, Culture and Identity. Harlow: Prentice Hall. Silva CF and Howe PD

(2012) The (in)validity of supercrip representation of Paralympian athletes. Journal of Sport \& Social Issues 36(2): 174-194.

Snyder S and Mitchell D (2001) Re-engaging the body: disability studies and the resistance to embodiment. Public Culture 13(3): 367-389.

Stokes M (2014) Bare Strength. Berlin: Bruno Gmunder. Stokes M (2015)

Always Loyal. Berlin: Bruno Gmunder.

Tynan J (2013) Military chic: fashioning civilian bodies for war. In: McSorley K (ed.) War and the Body: Militarisation, Practice and Experience. New York: Routledge, pp. 78-90.

Van Kraayenoord C (2009) Editorial: blindness, dancing with the stars, judgment and criteria. International Journal of Disability, Development and Education 56(4): 315-316.

Young IM (2003) The logic of masculinist protection: reflections on the current security state. Signs 29(1): 1-25.

Young IM (2005) On Female Body Experience: 'Throwing Like a Girl' and Other Essays. Oxford, NY: Oxford University Press. 